\title{
AMBIENTES VIRTUAIS DE ENSINO-APRENDIZAGEM: OS DESAFIOS DOS NOVOS ESPAÇOS DE ENSINAR E APRENDER E SUAS IMPLICAÇÕES NO CONTEXTO ESCOLAR
}

De Bastos, Fábio da Purificação*

Alberti, Taís Fim ${ }^{* *}$

Mazzardo, Mara Denize *** $^{* *}$

\section{Resumo}

Este trabalho relata uma experiência de um curso de formação para professores da educação básica, mediado por um Ambiente Virtual de Ensino-Aprendizagem (AVEA). Considerando o aprender sempre, a investigação e a análise reflexiva das práticas pedagógicas rotineiras, os avanços tecnológicos, os conhecimentos e informações de todas as áreas, a Formação Continuada para os Professores torna-se imperiosa. A Educação a Distância, via Internet, começa a ocasionar mudanças em todos os níveis de ensino. Os AVEA representam novas oportunidades de ensino-aprendizagem, pois comportam um grande número de informações, disponibilidade e acesso, independente de horários preestabelecidos e distâncias geográficas, possibilitam interação através de comunicação síncrona e assíncrona entre os participantes e trabalho colaborativo. $\mathrm{O}$ objetivo principal foi investigar, através da Investigação Ação Escolar (IAE), as potencialidades dos AVEA na formação continuada de professores, bem como, a prática escolar mediada pela tecnologia informática. Para concretizar os objetivos, montamos um curso - "Produção de Material Didático Através da Internet - O Saber e o Saber Ensinável", acoplando as modalidades presencial e a distância. Os resultados apontam os AVEA como um recurso potencializador das situações de formação, pois possibilitam aos professores continuarem aprendendo sem afastar-se de suas atividades profissionais, desenvolvendo um trabalho de forma colaborativa, dialógica e problematizadora.

Palavras-chave: Formação de Professores, Ambientes Virtuais de EnsinoAprendizagem, Investigação Ação-Escolar.

\begin{abstract}
This paper reports an experience in a basic education teacher's course thru a Virtual Environment for Teaching-Learning (AVEA in Portuguese). It's imperious the Teachers Continuous Formation for keeping in pace with the technological advancements, the new knowledge and information in every area in society. Distance Education thru the Internet starts to produce results in all teaching levels. Virtual Environment for Teaching-Learning have a wide range of information, availability and access, producing new learning-teaching opportunities, not depending on schedules and geographical

\footnotetext{
"Prof. Dr. Universidade Federal de Santa Maria/Dep. de Metodologia do Ensino/Programa de Pós-Graduação em Educação-fbastos@ce.ufsm.br

"Psicóloga, Mestranda pelo Programa de Pós-Graduação em Educação (PPGE)- Mestrado em Educação, pela

Universidade Federal de Santa Maria-tfalberti@mail.ufsm.br

*** Professora Multiplicadora do NTE Santa Maria, Mestranda pelo Programa de Pós-Graduação em Educação (PPGE)-

Mestrado em Educação, pela Universidade Federal de Santa Maria-mmazzardo@mail.ufsm.br
} 
distances, allowing synchronous and asynchronous between participants, as well as collaborative work. To verify the Virtual Environment for Teaching-Learning's potentialities for Continuing Education with School Action Research we set up a course "Didactical Material Production thru Internet - The Knowledge and the Teachable Knowledge", combining presence and distance modalities. The results show Virtual Environment for Teaching-Learning as a possible tool, with Dialog-Problematical Education, allowing teacher's learning while developing their professional activities.

\section{Keywords}

Teachers Formation, Virtual Environment for Teaching-Learning, School Action-

Research

\section{INTRODUÇÃO}

Considerando a necessidade de vivenciar situações de ensino-aprendizagem que envolvam recursos e procedimentos metodológicos inovadores no processo de Formação Continuada dos Professores e não somente ouvir sobre, lançamos desafios: de vivenciar situações de formação na busca de conhecimentos, discutindo a realidade escolar e a inserção dos recursos informáticos nesse contexto, inovando na produção de material didático, tendo a Internet e um AVEA como mediadores desse processo.

Outro desafio foi problematizar a forma como os professores percebem essa nova realidade, se estão vivenciando uma mudança cultural na sua prática didática com a inclusão dos recursos informáticos, explorando as potencialidades destes na educação, ou se esses recursos servem apenas como mais um meio de continuar repetindo as mesmas práticas, com a ilusão de inovação.

As atividades formativas propostas neste trabalho visaram proporcionar aos docentes, responsáveis pela organização do saber, vivenciar e compreender algumas formas de aplicação da tecnologia informática. Assim, a formação mediada por esses recursos, numa abordagem dialógico-problematizadora, pode mobilizar saberes da docência fazendo com que sejam críticos e investigadores de sua prática e com capacidade de avaliação.

Possibilitam, também, a busca de saberes, os quais podem ser pertinentes às suas aulas, através da transposição didática do material disponível na rede, tornando-se mais uma fonte para a produção de material didático, possibilitando interfaces entre educação e tecnologia.

Através do diálogo, procuramos nos perceber como sujeitos capazes de se incorporar no processo de mudanças e transformações no mundo e com o mundo (Freire, 1996). Nesse âmbito, poderíamos pensar na formação de uma cultura colaborativa, integrada e disposta a discutir e entender o significado e as mudanças que as tecnologias estão trazendo para o contexto escolar. Mudanças como a opção por software livre ou proprietário e as implicações educacionais decorrentes desta escolha.

A Educação, no escopo da Ciência e a Tecnologia, tem um lugar de destaque nas transformações da sociedade e na formação do sujeito que atua nessa sociedade. A adesão a essas tecnologias não deve acontecer de forma incondicional como se fosse solucionar todos os problemas da educação. Precisamos explorar as potencialidades desses recursos nas situações de ensino-aprendizagem e "evitar o deslumbramento que tende a levar ao uso mais ou menos indiscriminado da tecnologia por si e em si, ou seja, mais por suas virtualidades técnicas do que por suas virtudes pedagógicas" (Belloni, p. $73,2003)$. 
Por mais inovadora que seja, essa modalidade de ensino "não acontece sem a interação sistemática e planificada dos atores do processo educacional, alunos e professores, em torno da realização de algumas tarefas de aprendizagem" (Salvador Coll, 1994, p.102).

Enfim, tornar a tecnologia uma aliada, utilizando-se de novas estratégias e transformando práticas bancárias em um procedimento onde estejam envolvidas práticas colaborativas no processo de construção do conhecimento a partir da ação do sujeito.

De acordo com Freire (1981), práticas bancárias são práticas onde a escola se torna um ato de depositar, em que os educandos são os depositários e o educador o depositante. Em lugar de comunicar-se, o educador faz comunicados e depósitos que o educando recebe, memoriza e repete.

Dessa forma não há criatividade, colaboração e transformação. Assim, não há saber. Só existe saber na invenção, na reinvenção, na busca inquieta, impaciente, permanente, que o sujeito faz no mundo, com o mundo e com os outros.

Por isso, faz-se urgente uma educação em que se superem essas práticas e se pense no processo de ensinar e aprender como uma prática para a liberdade, pois, quanto mais o sujeito está comprometido com as transformações, mais estará implicado em buscar o conhecimento.

Trabalhando nessa perspectiva, os AVEA são uma nova possibilidade para a educação e precisam ser abordados através da educação dialógico-problematizadora. Portanto, são potencializadores de novas formas de desempenho profissional e para a busca de formação permanente.

\section{AVEA: NOVOS ESPAÇOS DE ENSINAR E APRENDER}

A educação a distância (EAD) está tomando forma e se inserindo no campo educacional como uma nova modalidade educacional, possibilitando que mais pessoas venham a buscar formação e qualificação. Ela se apresenta como uma inovação para suprir algumas carências na educação, relacionadas ao acesso a escolaridade, devido aos contextos sociais em que as pessoas se encontram, tornando o ensino mais abrangente. Pode ser mais um meio de viabilizar formação e atualização para os professores.

Com o surgimento da Internet, a EAD tomou um novo impulso. O que antes era feito por correspondência, rádio ou TV passa a ser mediado pelo computador conectado, possibilitando, inclusive, uma comunicação síncrona. Com sua implementação, muitas questões estão sendo retomadas (formação continuada, planejamento, organização e disposição de material didático, como redimensionar a forma de trabalhar) para garantir um ensino de qualidade. Nesse novo âmbito, mudam os espaços e tempos de ensinar e aprender. Muda a forma de organizarmos o trabalho escolar. O espaço é outro, e os AVEA surgem como possibilidade para que esse processo se articule.

Optamos por trabalhar com a abordagem AVEA (Mazzardo, 2004, p.10) e não apenas AVA (Ambiente Virtual de Aprendizagem) "para destacar e valorizar o papel do professor no planejamento e implementação das atividades didáticas desses ambientes." Acreditamos que, nessa abordagem, o processo se dê no par ensinar-aprender por ser um ambiente dialógico e problematizador.

Podemos denominar os AVEA como um ambiente que possui uma interface para navegação hipertextual que agrega múltiplas mídias, ferramentas de comunicação, síncrona e assíncrona, com proposta pedagógica, localizado em um único sítio.

Conforme Almeida (2003, p.05), esses ambientes nos "permitem integrar múltiplas mídias e recursos, apresentar informações de maneira organizada, desenvolver interações entre pessoas e objetos de conhecimento, elaborar e socializar produções tendo em vista atingir determinados objetivos." 
O AMEM - acessível no endereço http://amem.ce.ufsm.br) - é um Ambiente Multimídia de Educação Mediada por Computador, podendo ser usado como uma ferramenta didático-metodológica de apoio a professores que usam como organizadores do trabalho escolar a investigação-ação e educação dialógico-problematizadora (Lauerman 2002, disponível em http://amem.ce.ufsm.br/amem.php).

Foi desenvolvido por uma equipe multidisciplinar integrando profissionais da área de educação, informática e design, do Centro de Educação e Centro de Tecnologia da Universidade Federal de Santa Maria (UFSM).

O AVEA AMEM tem sido objeto de pesquisas, as quais podem ser conferidas nos trabalhos de Lauerman (2002) - Ambiente multimídia para educação mediada por computador na perspectiva da investigação-ação: avaliação e tutorial, disponível no módulo Ajuda; Fernández (2003) - Ambiente Multimídia para Educação mediada por computador na perspectiva da Investigação-Ação Educacional: modelagem e implemento; Mallmann (2004) - Monitoramento Eletrônico das Tarefas Extraclasse: Acoplando Aprendizagens Presencial e a Distância.

É baseado em Software Livre e é multiplataforma. Dá suporte para Educação Presencial, Semi-presencial e a Distância (Müller, F. M. et al, 2000). Contudo, como ferramenta tecnológica livre, por si só, não garante o diálogo-problematizador nas aulas. Para sustentar essa relação dialógica suas teorias-guias fundamentam-se em conceitos e teorias educacionais dialógico-problematizadores (Freire; 1981; 2002).

O acompanhamento e monitoramento pelo professor em torno das tarefas de aprendizagem são essenciais no processo de aquisição do conhecimento quando mediado pelas tecnologias de informação e comunicação (TIC). Assim, o professor acompanha todo o processo de ensino-aprendizagem e pode intervir quando necessário. Cabe a ele direcionar e monitorar a aprendizagem nesses novos espaços. As ações do professor direcionam-se no sentido de despertar a curiosidade, a dúvida, a pergunta, a investigação e a criação num ambiente em que, conforme Freire (1996), além de ensinar, o professor aprende, e o aluno, além de aprender, ensina.

Sendo assim, a educação mediada pelos AVEA acontece no respeito à diversidade, no diálogo, na autoria e na presença de um formador que tem o papel de criar as condições para que ocorra a aprendizagem, planejando, implementando, mediando quando necessário, ocasionando, assim, a interação entre professor e aluno, o que é fundamental para obtenção de resultados positivos. Na concepção de Silva (2003, p. 56), "o professor pode tornar-se um provocador do conhecimento. Em sala de aula online, ele será formulador de problemas, proponente de situações, arquiteto de percursos, mobilizador de inteligências múltiplas e coletivas na construção do conhecimento".

\section{CONTEXTO EM QUE FOI DESENVOLVIDO O TRABALHO}

Esta pesquisa foi desenvolvida no PPGE - Mestrado em Educação da UFSM, na Linha de Pesquisa de Formação de Professores. Nosso público alvo foram professores da Educação Básica da Rede Pública da cidade de Santa Maria - RS, que atuam em sala de aula, em unidades escolares que possuem Laboratório de Informática conectados à Internet.

Considerando a relevância dos procedimentos didáticos também nos AVEA e para não ficarmos somente no âmbito teórico, sugerimos uma modelização didáticometodológica que visa, além das habilidades no manejo dos recursos informáticos, a participação, o questionamento, o diálogo, a ação e as reflexões decorrentes das situações de formação. 
Essa modelização contemplou: situações de formação continuada, presencial e a distância, mediadas por tecnologias informáticas livres e um Ambiente Virtual de Ensino-Aprendizagem para Internet - o AMEM, Educação Dialógico-Problematizadora - EDP, a Investigação-ação Escolar - IAE e a Resolução de Problemas - RP.

O conteúdo trabalhado foi a busca de Saberes na Rede (da disciplina de atuação do professor e em consonância com os PCN) e a Transposição Didática. Estudo e discussão sobre os PCN e PCN+, Educação Mediada pelas Tecnologias Informáticas Livres, a Internet como repositório de Saber, onde encontrar os Saberes na Rede? Produção de Material Didático.

O planejamento foi feito observando-se os Três Momentos Pedagógicos Dialógico-Problematizadores (TMPDP) organizados por Abegg, De Bastos e Mallmann (2001) a partir da proposta de Angotti e Delizoicov (1990). Essa organização dos momentos pedagógicos da aula possibilita a estratégia de Resolução de Problemas, sendo assim estruturada: Desafio Inicial (DI), Melhor Solução Escolar do Momento (MSEM) e Desafio mais Amplo (DA), exemplificados na Figura 1:

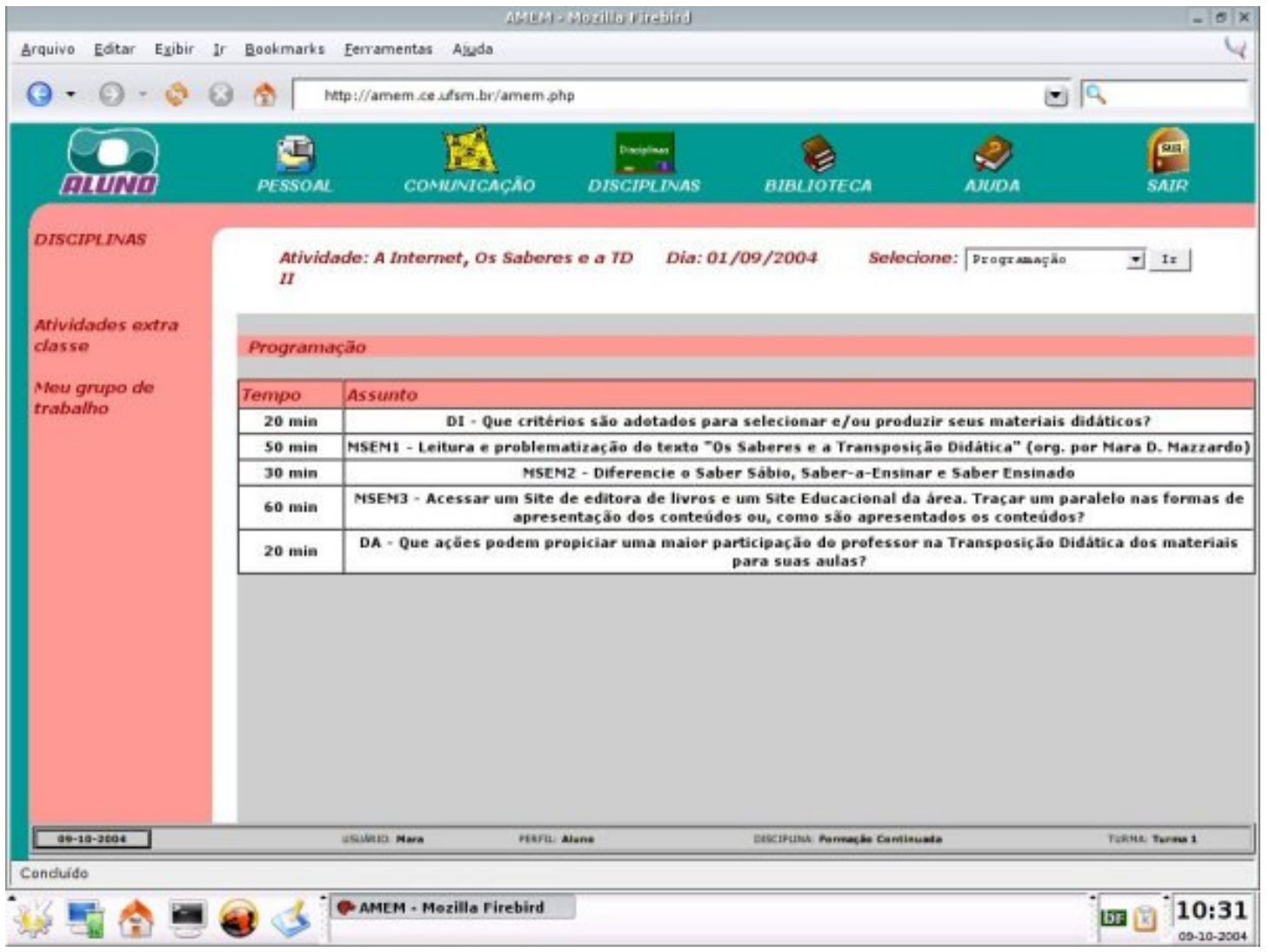

Figura 1 - Exemplo de aula disponibilizada no AMEM

Outras ferramentas do AMEM como Atividade de Colaboração, Tarefa Extraclasse, assim como Mensagens, Fóruns e a Biblioteca foram exploradas durante as atividades do curso.

Os recursos do AMEM são potencializadores dos objetivos escolares. Ao professor, possibilitam o Planejamento, Implementação, Monitoramento e Avaliação das atividades. Ao aluno, o acesso à Programação, às atividades a serem desenvolvidas nas situações presenciais e a distância, acesso à biblioteca, ao módulo comunicação (mensagens, fóruns) e outras ferramentas de apoio ao processo de ensino-aprendizagem. 
Quanto aos recursos que possibilitam a investigação, destacamos o campo Registro: Análise da Implementação - espaço para registrar, no próprio ambiente, as observações e análises sobre as questões de pesquisa investigadas em cada aula (Figura 2).

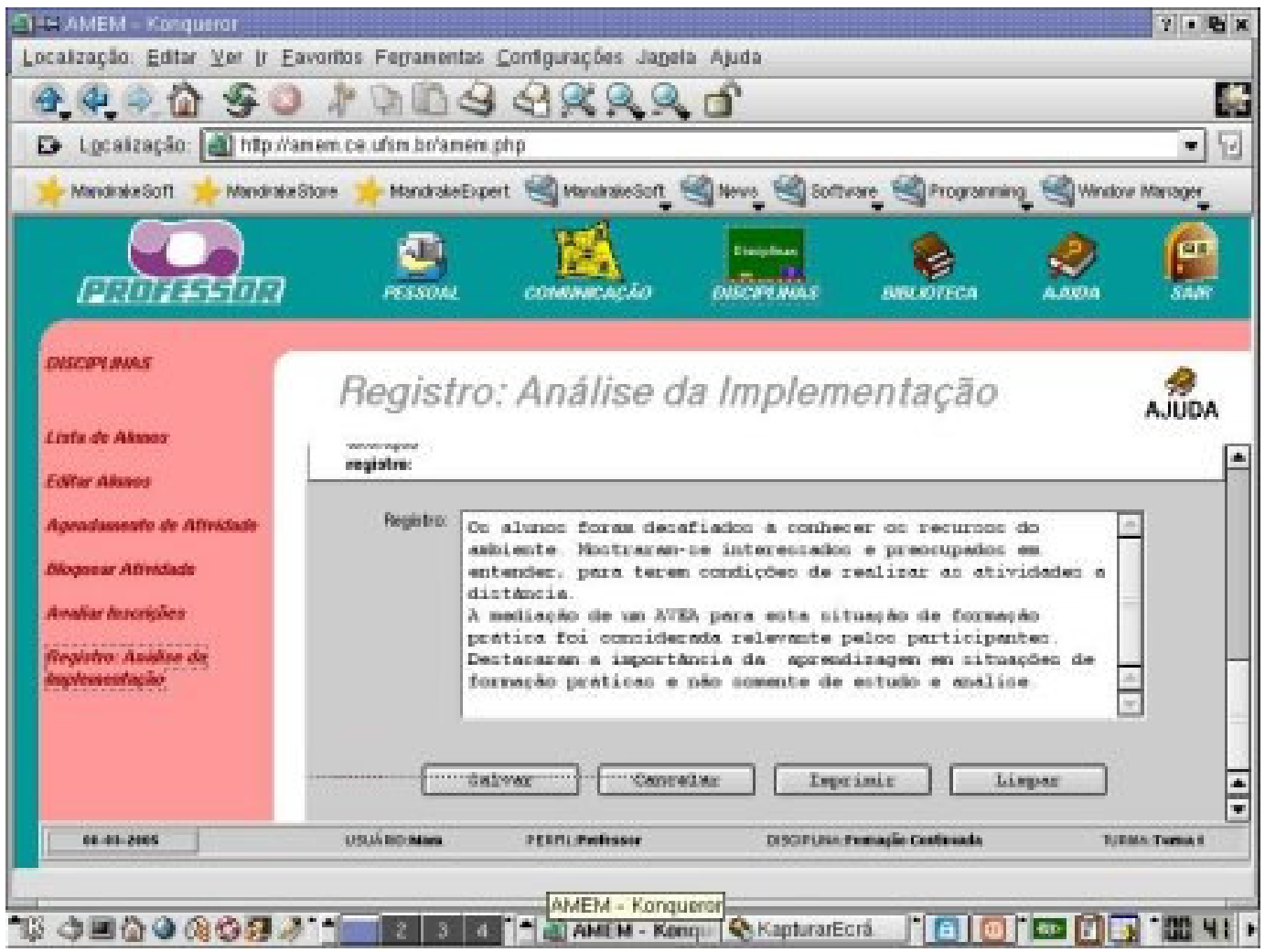

Figura 2 - Campo Registro: Análise da Implementação

Esses ambientes possibilitam ao professor tornar-se um investigador de sua prática e dos processos de ensino-aprendizagem nesse novo espaço de ensinar e aprender, tendo o recurso tecnológico como uma ferramenta de apoio para o planejamento de suas aulas, formação e pesquisa. Enfim, é mais uma possibilidade para se fazer educação.

\section{CONSIDERAÇÕES FINAIS}

Através das discussões, observações e reflexões ocorridas em todas as etapas planejamento, implementação, acompanhamento de todas as atividades e dos resultados obtidos - concluímos que os AVEA constituem-se em mais uma possibilidade de formação continuada para os professores da Educação Básica, principalmente quando acoplam as modalidades presencial e a distância. São novos espaços para ensinar e aprender.

Os AVEA expandem as relações espaço-temporais, o que permite o livre acesso ao andamento das atividades de qualquer lugar e a qualquer tempo (Almeida, 2003). Essa característica permite aos professores continuarem estudando desde seus locais de trabalho ou de sua residência de modo interativo.

Continuar aprendendo sem afastar-se de suas atividades profissionais e mantendo um vínculo com instituições formadoras vem ao encontro das necessidades formativas dos professores. 
Nestas novas maneiras e espaços de ensinar e aprender, as atividades a distância favorecem a participação, possibilitando formação continuada paralela ao trabalho e, as atividades presenciais suprem a necessidade "do real, do físico" de que ainda somos dependentes. Através do AMEM podemos acoplar as duas modalidades, exigindo do aluno uma maior participação, o que pode resultar em aprendizagem.

Observamos, também, alguns fatores que podem potencializar o ambiente e outros que dificultam o trabalho.

Os fatores que contribuíram para obtenção de resultados positivos foram: a) proposta metodológica; b) acompanhamento constante pelo professor das atividades do curso, estimulando a participação e realização das tarefas, provocando debates e questionamentos; c) discussão com o grupo sobre as dificuldades encontradas e busca de soluções para as mesmas; d) atendimento personalizado quando necessário; e) o interesse manifestado pelos professores por atividades mediadas pelos recursos informáticos na formação continuada e no processo ensino-aprendizagem; f) curiosidade epistemológica dos participantes do curso sobre a Internet e a necessidade de explorar as potencialidades pedagógicas da mesma; g) observação e reflexão constante sobre todo o processo formativo que estava sendo desenvolvido; $h$ ) estudo e discussão dos temas em situações de formação práticas, vivenciadas pelos participantes; i) Sujeitos se transformam - a proposta metodológica e os recursos mediadores deste trabalho exigiram mudanças para possibilitar a inserção nesses novos espaços de aprender e ensinar.

Os fatores que dificultaram o trabalho foram: a) a falta de familiaridade e fluência com os recursos tecnológicos informáticos, o que tornou as atividades mais complexas, dificultando a exploração das ferramentas do ambiente (participação nos fóruns, envio de mensagens, pesquisa na Biblioteca e nos Sites sugeridos, execução da Tarefa Extraclasse); b) o não contato, em sua rotina diária, da maioria dos professores com computadores conectados; c) a falta de uma rígida organização do tempo para estudo. A Educação a Distância, que atrai pela suposta facilidade, exige disciplina e dedicação dos estudantes, tempo disponível para leituras, realização das atividades e interação virtual com professores e colegas.

Os AVEA possibilitam trabalhar de forma colaborativa, dialógica e problematizadora, promovendo, assim, a interação entre todos os participantes. Porém, como essas atividades são incipientes nas situações de formação, os alunos participantes ainda não conseguiram identificar e explorar todo o potencial que os recursos do ambiente e a proposta metodológica possibilitam.

Com o avanço dos meios tecnológicos computacionais (MTC), os recursos dos AVEA cada vez mais possibilitam novas formas de interação e comunicação. Porém, lembramos que em um trabalho didático, mediado por um AVEA, é aconselhável selecionar alguns destes recursos e explorá-los adequadamente, evitando a superficialidade ocasionada pelo grande número de ferramentas. Esses recursos devem ser funcionais para que o aluno possa centrar sua atenção maior nos objetos de aprendizagem e não nos recursos tecnológicos.

Faz-se necessário continuar trabalhando, levando os participantes a melhorar a exploração dos recursos e entender que diálogo e interação também são possíveis pelo meio virtual, mesmo quando ocorrem de maneira assíncrona.

Freire (1996, p.79) já dizia "mudar é difícil, mas é possível". Esse processo de mudança requer muito esforço e uma caminhada que pode resultar em uma educação de qualidade. Sem investigar, não temos como conhecer, como saber das potencialidades dos AVEA e outros recursos tecnológicos no processo de ensino-aprendizagem. Nesse contexto, a busca de formação é um passo importante para que ocorram as mudanças necessárias no cenário educacional. 


\section{REFERÊNCIAS BIBLIOGRÁFICAS}

ABEGG, Ilse; DE BASTOS; Fábio da Purificação e MALlMANN, Elena. Maria. Momentos Pedagógicos Dialógico-Problematizadores: Sendo Desafiados nas Aulas. UFSM/PPGE, Santa Maria, 2001.

ALMEIDA, Maria Elizabeth Biancocini. Tecnologia e Educação a Distância: Abordagens e Contribuições dos Ambientes Digitais e Interativos de Aprendizagem. ANPEd, 2003.

ANGOTTI, José André Peres; DELIZOICOV, Demétrio. Metodologia do Ensino de Ciências. Cortez, São Paulo, 1990.

BELLONI, Maria Luiza. Educação a Distância. Campinas, SP, Autores Associados, 2003.

FERNANDEZ, Edgardo Gustavo Ambiente Multimídia para Educação Mediada por Computador na Perspectiva da Investigação-Ação Educacional: Modelagem e Implemento. Dissertação de Mestrado, PPGEP/CT/UFSM, 2003.

FREIRE, Paulo. Educação como Prática da Liberdade. 12. ed. Rio de Janeiro: Paz e Terra, 1981.

Pedagogia da Autonomia: Saberes Necessários à Prática Educativa. 11. ed. São Paulo: Paz e Terra, 1996.

Pedagogia do Oprimido. 32. ed. Rio de Janeiro: Paz e Terra, 2002.

LAUERMANN, Rosiclei Aparecida Cavichioli. Ambiente Multimídia para Educação Mediada por Computador na Perspectiva da Investigação-Ação: Avaliação e Tutorial. Dissertação de Mestrado, PPGEP/CT/UFSM, Santa Maria, 2002.

MALLMANN, Elena Maria. Monitoramento Eletrônico das Tarefas Extraclasse: Acoplando Aprendizagens Presencial e a Distância. Dissertação de Mestrado, PPGE/UFSM, Santa Maria, 2004.

MAZZARDO, Mara Denize. As Potencialidades dos Ambientes Virtuais de EnsinoAprendizagem, para a Internet, na Formação Continuada de Professores. Projeto (Dissertação de Mestrado) - Universidade Federal de Santa Maria, Santa Maria, 2004.

MÜLLER, Felipe Martins. et. al. Ambiente Multimídia para Educação Mediada por Computador na Perspectiva da Investigação-ação. Projeto de Pesquisa, FAPERGS, Santa Maria, RS, 2000.

SALVADOR, César Coll. Aprendizagem Escolar e Construção do Conhecimento. Porto Alegre : Artes Médicas, 1994. 
$-\int$ CINTED-UFRGS Novas Tecnologias na Educação

SILVA, Marco. Criar e Professorar um Curso Online: Relato de Experiência. In SILVA, Marco (org). Educação Online: Teorias, Práticas, Legislação, Formação Corporativa. 1. ed. Rio de Janeiro: Loyola, 2003. 